\title{
Catalytic Condensation of Depithed Sugarcane Bagasse Derived Levulinic Acid into Diphenolic Acid
}

\author{
Lethiwe Debra Mthembu, ${ }^{\mathrm{a}, *}$ David Lokhat, ${ }^{\mathrm{b}}$ and Nirmala Deenadayalu ${ }^{\mathrm{a}}$ \\ Levulinic acid (LA) is a platform chemical that can be produced from \\ biomass. Diphenolic acid (DPA) is a derivative of LA with the potential to \\ replace bisphenol $A$, a plasticizer. To determine the optimum conditions \\ for DPA production, commercial LA was used with a mild environmentally \\ benign acid, namely, methanesulfonic acid (MsOH). The optimized \\ reaction parameters were time $(6 \mathrm{~h})$, temperature $\left(75^{\circ} \mathrm{C}\right)$, and catalyst \\ loading $(5.5 \mathrm{~g})$, yielding $65.8 \%$ DPA at $90 \%$ LA conversion. The response \\ surface methodology (RSM) study indicated that the temperature had the \\ most significant effect on DPA yield, followed by time and catalyst loading. \\ The analysis of variance (ANOVA) revealed that the model was able to \\ satisfactorily predict the DPA yield. To determine the effect of catalyst on \\ DPA production from commercial LA, ionic liquids (ILs), $\mathrm{MsOH}$, and \\ sulfuric acid were used. IL catalysts produced 59 to $68 \%$ of DPA, MsOH \\ produced $65.6 \%$ of DPA, and sulfuric acid produced the maximum DPA of \\ $74 \%$. The study of LA: phenol ratio revealed that more reactants $(2: 5)$ \\ yielded the most DPA (86.35\%). The optimized reaction conditions were \\ then used to produce DPA from LA derived from depithed sugarcane \\ bagasse (DSB), which yielded $64.5 \%$ of DPA.
}

Keywords: Condensation; Levulinic acid; Diphenolic acid; Depithed sugarcane bagasse; Methanesulfonic acid

Contact information: a: Department of Chemistry, Durban University of Technology, Steve Biko Road, Berea, Durban, 4001, South Africa; b: Discipline of Chemical Engineering, University of KwaZulu-Natal, Durban 4041, South Africa; *Corresponding author: 21451030@dut4life.ac.za

\section{INTRODUCTION}

The biorefinery concept, whereby biomass waste can be used to synthesize valuable chemicals, has received enormous attention over the years because of the depletion of fossil fuels and the negative climate change effects associated with the latter. Sugarcane (Saccharum officinarum) is a major crop in Africa, South America, and Asia, containing sucrose stored in the stalk (Chambon et al. 2018). When the sugarcane stalks are mixed with water and crushed to make sugar, the solid residue that results is called sugarcane bagasse (SB), which consists of hemicellulose (25.63 wt\%), lignin (30.36 wt \%), and cellulose (39.53 wt\%) (Zhao et al. 2002). Even though sugarcane bagasse is used to power sugar mills, as well as in paper and tissue production, there is still excess of SB. As one of the largest agro-industrial processes in the world, it is estimated that over 500 million wet tons ( $\sim 250$ million dry tons) of sugarcane bagasse are produced annually (Chambon et al. 2018). The excess bagasse may be used to produce chemicals. When the pith is removed from SB, the resulting SB is called depithed sugarcane bagasse (DSB) (Mthembu et al. 2020). When original bagasse (mill-run bagasse) was compared with the depithed sugarcane bagasse (Mkhize et al. 2016), it was discovered that DSB is easier to handle, and it contains slightly more glucose. Hence, DSB was used in this study. Levulinic acid 
(LA) has been identified as one of the sugar-derived platform chemicals that can be produced from lignocellulosic biomass through hydrolysis or dehydration of hexose sugars (Bozell et al. 2000; Cha and Hanna 2002; Chen et al. 2011; Yan et al. 2013; Yan and Chen 2013).

Diphenolic acid (4,4-bis(4-hydroxyphenyl)pentanoic acid or 4,4-bisphenoxy pentanoic acid or 4-(bis(hydroxyphenyl))pentanoic acid) is a derivative of LA that is prepared by the condensation reaction of LA with phenol (Hayes et al. 2006). DPA has wide practical uses and extensive application value in the synthesis of polymeride (Kitano et al. 1976), which is a feedstock for the production of water-soluble resins that are used in industrial Millipore and oil filter papers (Kitano et al. 1976; Zhang et al. 2012; Mthembu 2016). DPA is also a widely used chemical intermediate in paints (Holmen and Olander 1977), protective and decorative coatings (Blegen 1982), lubricants (Chafetz et al. 1995), cosmetics, surfactants, plasticizers and polymers (Bozell and Petersen 2000), and textile chemicals (Liu et al. 2012; Shen et al. 2014; Zuñiga et al. 2017). DPA is a structural analog of bisphenol A (BPA) and can serve in many of the same applications as BPA, namely, for the synthesis of industrially important epoxy resins and polycarbonates that are used in the production of reinforced plastics and other chemical materials (Yu et al. 2008; Ertl et al. 2014).

The traditional reaction for DPA production is the condensation reaction of phenol with LA in the presence of a catalyst, usually hydrochloric acid $(\mathrm{HCl})$ or sulfuric acid $\left(\mathrm{H}_{2} \mathrm{SO}_{4}\right)$ (Liu et al. 2013; Ertl et al. 2014). However, most mineral acids are toxic and corrosive, produce various unnecessary side-products that are difficult to separate from the reaction media, and result in expensive waste treatment (Yu et al. 2008; Shen et al. 2014). Therefore, solid catalysts have been used as a replacement for mineral acids (Guo et al. 2007; Li et al. 2009). Even though greener solid catalysts have been used for the condensation of LA into DPA, there are some drawbacks, which include low catalytic active sites and high susceptibility to leaching (Shen et al. 2014).

To overcome some of the shortcomings of mineral acids and solids catalyst, ionic liquids (ILs) have been used as a catalyst for DPA production (Shen et al. 2014). ILs are considered as green solvents/catalysts due to their low vapor pressure, high thermal stability, and low flammability (Zhang et al. 2015). The added advantage of using the IL over the acid, besides the high yield, is that it can be recycled and is non-volatile. Liu et al. (2013) used thiol-containing acid ILs for DPA production, which resulted in a high DPA yield (>90\%); however, there is a limitation that is associated with high cost of the ILs. Other disadvantages of using ILs include long reaction time $(24 \mathrm{~h})$ to achieve high DPA yield (Shen et al. 2014) and the long reaction time implies higher energy usage. There is a need for a green catalyst for DPA production from LA.

In this work, DPA production was optimized using commercial LA and methanesulfonic acid as the control catalyst. Response surface methodology (RSM) was used to optimize this study. A Box-Behnken design (BBD) was used to produce a set of experiments for the optimisation process. Various other catalysts, namely tosylic acid [TsOH], 1-butyl-3-methylimidazolium hydrogen sulphate [BMim][HSO4], 1-ethyl-3methylimidazolium tosylate [EMim][OTs], and sulfuric acid $\left[\mathrm{H}_{2} \mathrm{SO}_{4}\right]$ were used to determine the effect of the catalysts for DPA production from commercial LA. The optimization parameters were time, temperature, and catalyst loading. The optimized reaction conditions were used to produce DPA from LA derived from DSB. Figure 1 illustrates the production of DPA, including the formation of the two isomers ( $\mathrm{p}, \mathrm{p}$ ' and o,p') from LA derived from DSB.

Mthembu et al. (2021). "Diphenolic acid from bagasse," BioResources 16(2), 2235-2248. 2236 


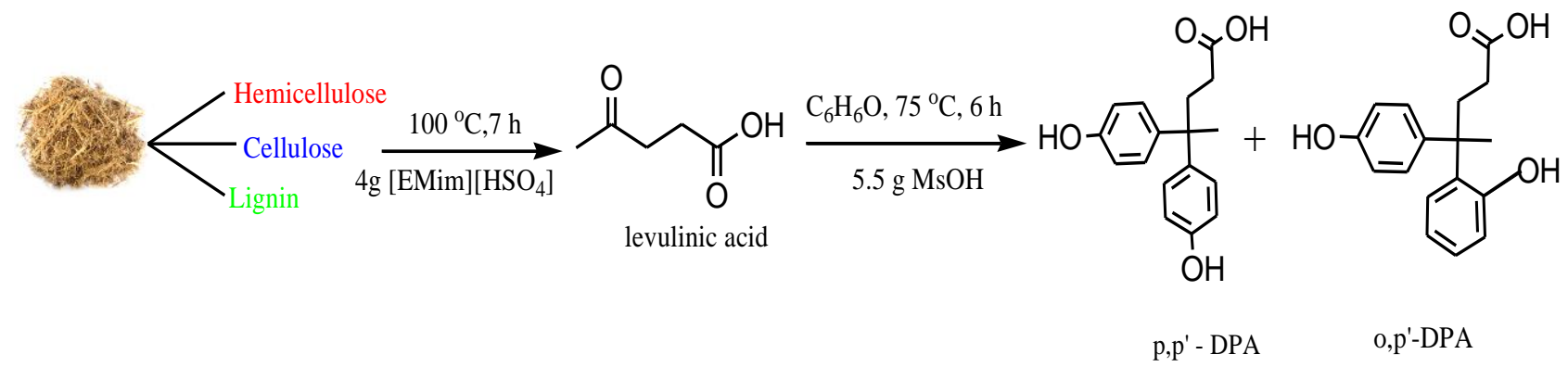

Fig. 1. DPA (p,p' and o,p') production from LA and phenol in the presence of a catalyst

\section{EXPERIMENTAL}

\section{Materials}

All chemicals were purchased from Merck (Johannesburg, South Africa) and were used without any further purification. The chemicals included levulinic acid (99\%), phenol (95\%), methanesulfonic acid (98\%), p-toluenesulfonic acid monohydrate ( $\geq 98.5 \%)$, methanol (98\%), acetonitrile (99\%), 1-butyl-3-methylimidazolium hydrogen sulphate $(\geq$ $95 \%)$, 1-ethyl-3-methylimidazolium tosylate ( $\geq 98 \%$ ), sulfuric acid (98\%), and 1-ethyl3-methylimidazolium hydrogen sulfate $(95 \%)$.

\section{Methods}

Compositional analysis of DSB

The DSB was dried in an oven (Scientific, South Africa) at $105^{\circ} \mathrm{C}$ for $24 \mathrm{~h}$, milled using a Pulverisette 16 (Fritsch, Germany), and sieved to 40-mesh particle size. The procedure used for compositional analysis of DSB is explained in our previous study (Mkhize et al. 2016).

Optimization of DPA production using methanesulfonic acid ( $\mathrm{MsOH}$ )

To determine the optimum reaction conditions for DPA production from commercial LA, the minimum and maximum reaction conditions are given in Table 1 and were used in the BBD to derive the set of experiments (Table 2). A constant mass of $5.0 \mathrm{~g}$ of commercial LA, $15 \mathrm{~g}$ of phenol (LA: phenol ratio of 1:3), and a predetermined amount of $\mathrm{MsOH}$ catalyst (Table 2) were placed in a PTF liner and inserted into a $100 \mathrm{~mL}$ Parr batch reactor (Parr Instruments Company, Moline, IL, USA).

Table 1. Investigated Minimum and Maximum Reaction Parameters for LA Conversion into DPA Using BBD

\begin{tabular}{|c|c|c|c|}
\hline \multirow{2}{*}{ Factors } & \multicolumn{3}{|c|}{ Range and Level } \\
\cline { 2 - 4 } & -1 & 0 & +1 \\
\hline Time $(\mathrm{h})$ & 2 & 6 & 10 \\
\hline Temperature $\left({ }^{\circ} \mathrm{C}\right)$ & 25 & 75 & 125 \\
\hline Catalyst loading $(\mathrm{g})$ & 1 & 5.5 & 10 \\
\hline
\end{tabular}


The reaction time and temperature were varied for each experiment according to Table 2. The reaction mixture was stirred at $200 \mathrm{rpm}$, and the duration of the reaction was measured from the time the set temperature was reached. At the end of the reaction, the heat supply was quickly removed, and the reactor vessel was inserted into a cold-water bath $\left(5^{\circ} \mathrm{C}\right)$ to cool the vessel and the reaction to room temperature. A sample of $20 \mathrm{~mL}$ of methanol was added to the cooled mixture, and the reaction product was stored at $4{ }^{\circ} \mathrm{C}$.

Effect of the catalyst on the production of DPA

The optimized reaction conditions obtained using methanesulfonic acid and the commercial LA were used for four other catalysts: tosylic acid (TsOH), 1-butyl-3methylimidazolium hydrogen sulphate [BMim][HSO 4$]$, 1-ethyl-3-methylimidazolium tosylate [EMim][OTs], and sulfuric acid $\left[\mathrm{H}_{2} \mathrm{SO}_{4}\right]$.

\section{Effect of LA to phenol ratio on DPA production}

To determine the effect of LA to phenol ratio on the DPA production, the ratio of commercial LA and phenol was varied based on the optimized reaction conditions. The ratio of 1:3 was used as a control. The investigated ratios of commercial LA to phenol were $1: 4,1: 5,2: 3,2: 4$, and $2: 5$.

\section{DSB Conversion to DPA}

\section{Conversion of DSB to $L A$}

The procedure for the production of LA from DSB was similar to that used in a previous study (Mthembu et al. 2020). For this study, the production was upscaled from the ratio 1:4, i.e., $1 \mathrm{~g}$ of bagasse and $4 \mathrm{~g}$ of 1-ethyl-3-methylimidazolium hydrogen sulfate [EMim] $\left[\mathrm{HSO}_{4}\right]$ to $100 \mathrm{~g}$ of bagasse and $400 \mathrm{~g}$ of [EMim] [HSO 4 ]. The reaction was carried out in a round bottom flask immersed in an oil bath for $7 \mathrm{~h}$ at $100{ }^{\circ} \mathrm{C}$.

\section{Condensation reaction of $L A$ derived from DSB into DPA}

The LA derived from DSB was used to produce DPA using the optimized conditions, replacing the commercial LA.

\section{Product Analysis}

HPLC characterization

The concentration of DSB derived LA and DPA were analysed by high performance liquid chromatography (HPLC) (Shimadzu, Kyoto, Japan) equipped with a $\mathrm{C} 18$ column $(150 \times 4.6 \mathrm{~mm})$ at flow rate of $1.0 \mathrm{~mL} / \mathrm{min}$ with a column temperature of 40 ${ }^{\circ} \mathrm{C}$ and using an ultraviolet (UV) detector at $270 \mathrm{~nm}$. The mobile phase was water and acetonitrile $(40 \%)$. Using a syringe, $1 \mathrm{~mL}$ of samples and standards were filtered over a 0.45-micron filter to prevent any solids to enter the HPLC column and then injected into the HPLC system for analysis. The total retention time was $20 \mathrm{~min}$. Both samples and standards were dissolved in methanol. The concentration of DPA was calculated using a standard calibration curve. The retention time of p,p'- DPA, o,p'- DPA, and LA were 5, 7, and $10 \mathrm{~min}$, respectively.

\section{Equations}

The DPA yield $\left(Y_{D P A}\right)$, combination of the two isomers (p,p'-DPA and o,p'-DPA), actual yield $\left(Y_{\text {act }}\right)$, theoretical yield $\left(Y_{t h}\right)$, LA conversion $\left(X_{L A}\right)$, and DPA selectivity $\left(S_{D P A}\right)$ were calculated from Eqs. 1 through 5, 


$$
\begin{aligned}
& Y_{D P A}(\%)=\frac{Y_{a c t}}{Y_{t h}} \times 100 \\
& Y_{a c t}=\frac{D P A \text { experimental mass }(g)}{\text { Mass of initial feedstock }(g)} \\
& Y_{t h}=n_{L A} \times M r_{D P A} \\
& X_{L A}(\%)=\frac{C_{L A, O}-C_{L A}}{C_{L A, O}} \times 100 \\
& S_{p, p^{\prime}-D P A \text { or o,p },-D P A}(\%)=\frac{n_{p, p^{\prime}-D P A} \text { Or } n_{o, p^{\prime}-D P A}}{\left(n_{p, p^{\prime}-D P A}+n_{o, p^{\prime}-D P A}\right)} \times 100
\end{aligned}
$$

where $n_{L A}$ is the number of moles of LA, $M r_{D P A}$ is the molar mass of DPA,LA molar mass is $116.11 \mathrm{~g} \cdot \mathrm{mol}^{-1}$, and DPA molar mass is $286.33 \mathrm{~g} \cdot \mathrm{mol}^{-1}, C_{L A, O}$ is the initial concentration of LA, $C_{L A}$ is the concentration of LA, $S$ is the selectivity (\%), and $n_{\mathrm{p}, \mathrm{p}^{\prime} \text {-DPA }}$ or $n_{\mathrm{o}, \mathrm{p}^{\prime}-\mathrm{DPA}}$ is the number of moles of p,p'-DPA or o,p'-DPA.

\section{RESULTS AND DISCUSSION}

\section{DSB Compositional Analysis}

The compositional analysis of DSB revealed that DSB consists of about $44 \%$ cellulose, 21\% hemicellulose, and 25\% lignin. The compositional analysis of DSB in this work was within the range of the literature values: 40 to $44 \%$ cellulose, 26 to $29 \%$ hemicellulose, and 22 to 30\% lignin (Chandel et al. 2014; Chambon et al. 2018).

\section{Optimization of DPA Production from Commercial LA using MsOH}

Table 2 lists the DPA yield (\%), commercial LA conversion (\%), and $p, p$ 'DPA/o, $p$ '-DPA selectivity (\%). The optimum reaction conditions were $6 \mathrm{~h}$ (time), $75{ }^{\circ} \mathrm{C}$ (temperature), and $5.5 \mathrm{~g}$ (catalyst loading), yielding $65.8 \%$ of DPA. In Table 2 (run 12), where the lowest $\%$ LA conversion occurred (46\%), the factors that had the least effect were temperature $\left(75^{\circ} \mathrm{C}\right)$ and catalyst loading $(10 \mathrm{~g})$, and the factor that had the greatest effect was time $(2 \mathrm{~h})$. For run 4 with the same temperature and loading but a different time $(10 \mathrm{~h})$ the LA conversion was $90 \%$, so the variable time could give a difference as large as $44 \%$ in the \% conversion of LA which is significant. A similar trend can be observed for percent DPA conversion (runs 1 and 6), where the percentage of DPA produced increased from $21.1 \%$ to $32 \%$, respectively, when time increased from $2 \mathrm{~h}$ to $10 \mathrm{~h}$. The reproducibility was high because 5 experiments $(2,8,10,14$, and 16) using the same reaction conditions had a response difference within $+/-2 \%$. The optimum conditions favour higher selectivity of the p,p'-DPA isomer. 
Table 2. Experimental Conditions, DPA Yield, LA Conversion (\%), p, p'-DPA/o, $p^{\prime}-$ DPA Selectivity (\%)

\begin{tabular}{|c|c|c|c|c|c|c|c|}
\hline \multirow[t]{2}{*}{$\begin{array}{c}\text { Experiment } \\
\text { No. }\end{array}$} & $\begin{array}{c}\text { Factor } \\
1\end{array}$ & Factor 2 & Factor 3 & Response & \multirow[t]{2}{*}{$\begin{array}{c}\mathrm{LA} \\
\text { conversion } \\
X_{\mathrm{LA}}(\%)\end{array}$} & \multirow[t]{2}{*}{$\begin{array}{c}p, p^{\prime}-\mathrm{DPA} \\
\text { selectivity } \\
\text { SDPA }(\%)\end{array}$} & \multirow[t]{2}{*}{$\begin{array}{l}\text { o,p'-DPA } \\
\text { selectivity } \\
\text { SDPA (\%) }\end{array}$} \\
\hline & $\begin{array}{c}\text { A: } \\
\text { Time } \\
\text { (h) }\end{array}$ & $\begin{array}{c}\mathrm{B}: \\
\text { Temperature } \\
\left({ }^{\circ} \mathrm{C}\right)\end{array}$ & $\begin{array}{c}\text { C: } \\
\text { Catalyst } \\
\text { load }(\mathrm{g})\end{array}$ & $\begin{array}{c}\text { DPA yield } \\
Y_{\text {DPA }}(\%)\end{array}$ & & & \\
\hline 1 & 2 & 75 & 1 & 21.1 & 70 & 74.1 & 26.0 \\
\hline 2 & 6 & 75 & 5.5 & 65.8 & 90 & 55.5 & 44.5 \\
\hline 3 & 6 & 125 & 1 & 38.8 & 89 & 61.2 & 38.8 \\
\hline 4 & 10 & 75 & 10 & 46.9 & 90 & 51.2 & 48.8 \\
\hline 5 & 10 & 25 & 5.5 & 44.2 & 78 & 59.1 & 40.9 \\
\hline 6 & 10 & 75 & 1 & 32 & 75 & 54.9 & 45.1 \\
\hline 7 & 2 & 125 & 5.5 & 46.7 & 88 & 57.9 & 42.1 \\
\hline 8 & 6 & 75 & 5.5 & 64.8 & 87 & 57.5 & 42.5 \\
\hline 9 & 10 & 125 & 5.5 & 61.4 & 89 & 51.0 & 49.0 \\
\hline 10 & 6 & 75 & 5.5 & 65.1 & 88 & 58.8 & 41.2 \\
\hline 11 & 6 & 25 & 1 & 30.9 & 68 & 60.2 & 39.8 \\
\hline 12 & 2 & 75 & 10 & 27.2 & 46 & 88.0 & 12.0 \\
\hline 13 & 2 & 25 & 5.5 & 28.9 & 78 & 67.5 & 32.5 \\
\hline 14 & 6 & 75 & 5.5 & 64.5 & 87 & 55.3 & 44.7 \\
\hline 15 & 6 & 125 & 10 & 58.6 & 70 & 57.5 & 42.5 \\
\hline 16 & 6 & 75 & 5.5 & 64.9 & 89 & 55.8 & 44.2 \\
\hline 17 & 6 & 25 & 10 & 34.6 & 69 & 57.5 & 42.5 \\
\hline
\end{tabular}

Equation 6 has the coded factors for the parameters and was used to make predictions about the response for given levels of each factor. By default, the high levels of the factors are coded as +1 and the low levels are coded as -1 . The coded equation is useful for identifying the relative impact of the factors by comparing the factor coefficients.

$$
\begin{aligned}
\text { DPA yield }(\%)= & 65.02+7.57 A+8.36 B+5.56 C \\
& 0.1500 A B+2.20 A C-4.03 B C \\
& 14.32 A^{2}-5.40 B^{2}-18.90 C^{2}
\end{aligned}
$$

Table 3. ANOVA for the Response Surface Methodology Results

\begin{tabular}{|c|c|c|c|c|c|}
\hline Source & $\begin{array}{c}\text { Sum of } \\
\text { Squares }\end{array}$ & df & Mean Square & F-value & P-value \\
\hline \multicolumn{7}{|c|}{$\mathrm{R}^{2}=0.9993$} \\
\hline Model & 4066.71 & 9 & 451.86 & 1063.01 & $<0.0001$ \\
\hline A-Time & 459.04 & 1 & 459.04 & 1079.92 & $<0.0001$ \\
\hline B-Temperature & 559.45 & 1 & 559.45 & 1316.13 & $<0.0001$ \\
\hline C- Catalyst loading & 247.53 & 1 & 247.53 & 582.33 & $<0.0001$ \\
\hline AB & 0.0900 & 1 & 0.0900 & 0.2117 & 0.6594 \\
\hline AC & 19.36 & 1 & 19.36 & 45.55 & 0.0003 \\
\hline BC & 64.80 & 1 & 64.80 & 152.45 & $<0.0001$ \\
\hline $\mathrm{A}^{2}$ & 863.72 & 1 & 863.72 & 2031.95 & $<0.0001$ \\
\hline $\mathrm{B}^{2}$ & 122.67 & 1 & 122.67 & 288.58 & $<0.0001$ \\
\hline $\mathrm{C}^{2}$ & 1503.64 & 1 & 1503.64 & 3537.39 & $<0.0001$ \\
\hline Residual & 2.98 & 7 & 0.4251 & & \\
\hline Lack of Fit & 2.03 & 3 & 0.6758 & 2.85 & 0.1687 \\
\hline Pure Error & 0.9480 & 4 & 0.2370 & & \\
\hline Corrected Total & 4069.68 & 16 & & & \\
\hline
\end{tabular}


Table 3 displays the ANOVA for DPA yield. The model F-value of 1063.01 implies that the model is significant. There is only a $0.01 \%$ chance that an F-value this large could occur due to noise. $\mathrm{P}$-values less than 0.0500 indicate model terms are significant. In this case $\mathrm{A}, \mathrm{B}, \mathrm{C}, \mathrm{AC}, \mathrm{BC}, \mathrm{A}^{2}, \mathrm{~B}^{2}$, and $\mathrm{C}^{2}$ are significant model terms. The lack of fit F-value of 2.85 implies that the model is fit to predict the DPA yield. The coefficient of determination $\left(\mathrm{R}^{2}\right)$ is 0.9993 which is close to one indicating that the model is significant.

The parity plot in Fig. 2 compared the experimental and predicted DPA yield. There is excellent agreement between the experimental and predicted responses.

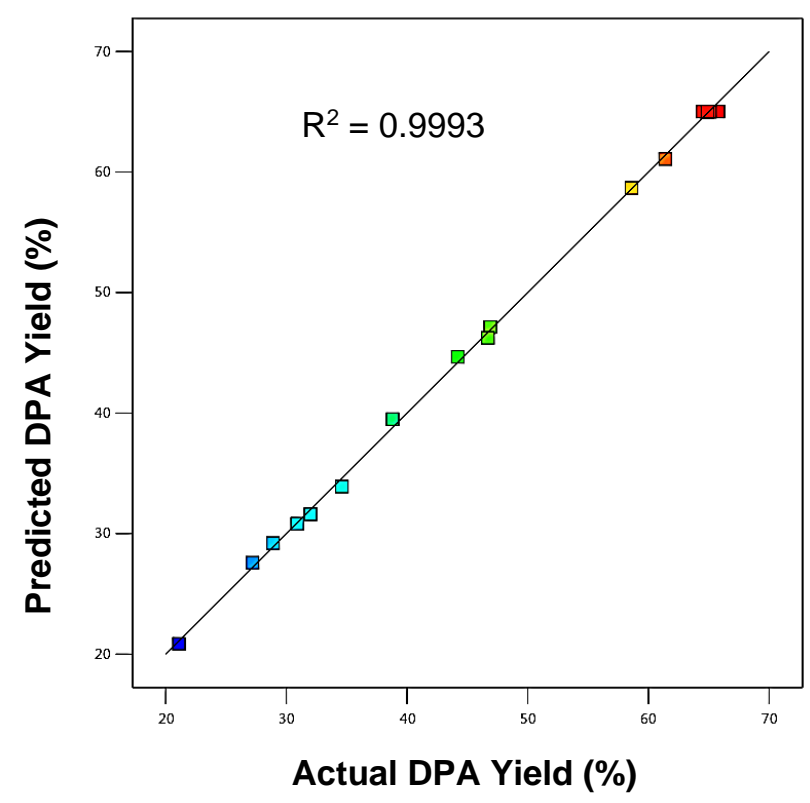

Fig. 2. DPA parity plot which compares the predicted DPA yield with the experimental DPA yield

The Pareto chart in Fig. 3 illustrates which factors have a high impact on the DPA yield. According to Fig. 3 the factors that have a high impact on DPA yield are temperature (B) followed by time (A), and catalyst loading (C).

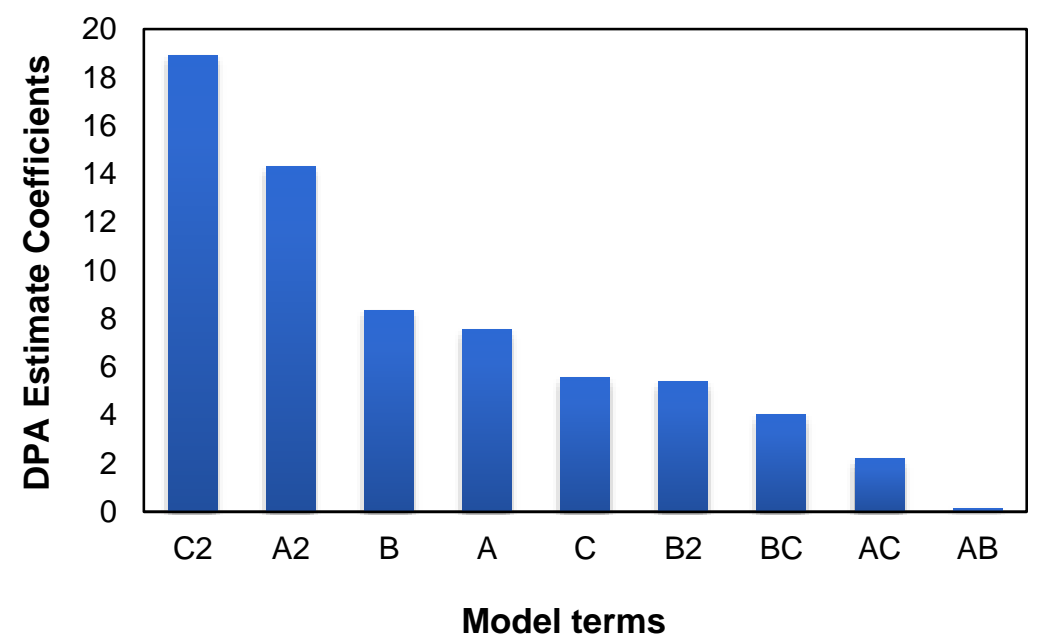

Fig. 3. Pareto chart for DPA yield, determining the most influential model term on DPA production 
To study the interaction of the investigated factors in the production of DPA, RSM was used. The 3D response surface and contour plots are shown in Fig. 4 a-c, where two factors and the response were evaluated while one factor remained at the optimum condition.

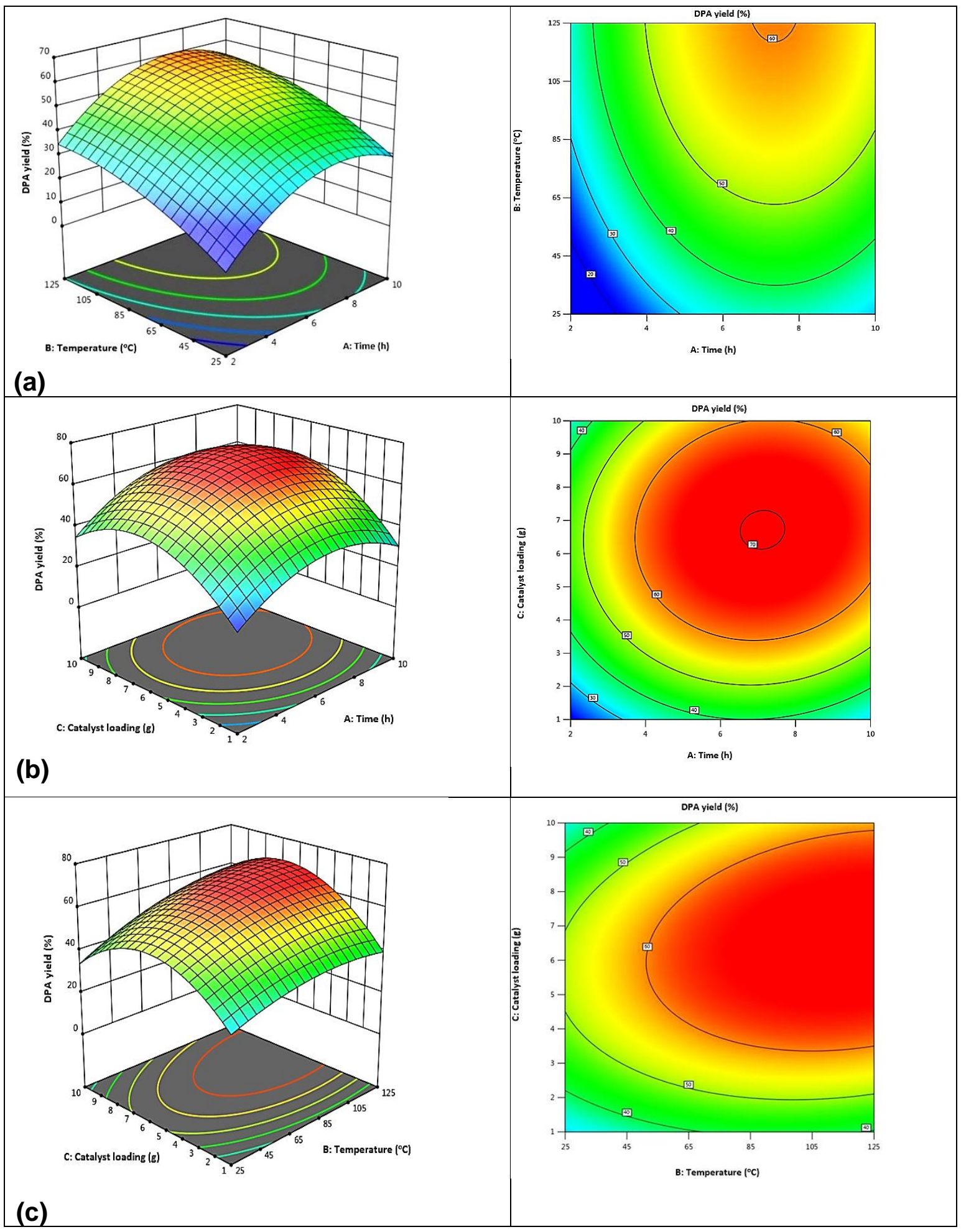

Fig. 4. 3D response surface and contour plots for the interaction of the investigated factors (a) temperature $v s$. time, (b) catalyst loading $v s$. time, and (c) catalyst loading vs. temperature 
Figure 4a illustrates the interaction between temperature and reaction time, the investigated range of temperature $\left(25\right.$ to $\left.125^{\circ} \mathrm{C}\right)$ and 2 to $10 \mathrm{~h}$ for the reaction time. The temperature of $75^{\circ} \mathrm{C}$ and the reaction time of $6 \mathrm{~h}$ yielded maximum DPA. Figure $4 \mathrm{a}$ shows that the minimum and maximum of temperature, and time yields lower DPA, whereas the moderate conditions favour the maximum production of DPA. Figure $4 \mathrm{~b}$ illustrates the interaction between catalyst loading and time, the reaction was carried out at 1 to $10 \mathrm{~g}$ and 2 to $10 \mathrm{~h}$. The DPA yield increased with increasing catalyst loading and time. Figure $4 \mathrm{~b}$ shows that a catalyst loading of $5.5 \mathrm{~g}$ and a reaction time of $6 \mathrm{~h}$ yielded maximum DPA yield. Figure $4 \mathrm{c}$ shows the interaction between catalyst loading and temperature that shows increasing the catalyst loading from 1 to $5.5 \mathrm{~g}$ increased the DPA yield. Increasing the catalyst loading to $10 \mathrm{~g}$ decreased the DPA yield. The optimum conditions were temperature of $75{ }^{\circ} \mathrm{C}$, time of $6 \mathrm{~h}$, and catalyst loading of $5.5 \mathrm{~g}$ yielding $65.8 \%$ of DPA.

From Fig. 4 a-c it is observed that less catalyst resulted in lower yield. This was possibly due to lower overall reaction rate. Higher catalyst loadings coupled with longer reaction times results in lower yields, which could be due to degradation of the catalyst due to prolonged reaction times. Higher temperatures did not have a huge impact on the yield, but higher temperatures coupled with a higher catalyst loading reduced the yield. In summary, higher catalyst loading had a negative impact on the yield.

\section{DPA FTIR Characterization}

The FTIR characterization of optimized DPA obtained from commercial LA is illustrated in Fig. 5 compared with a standard sample of DPA.

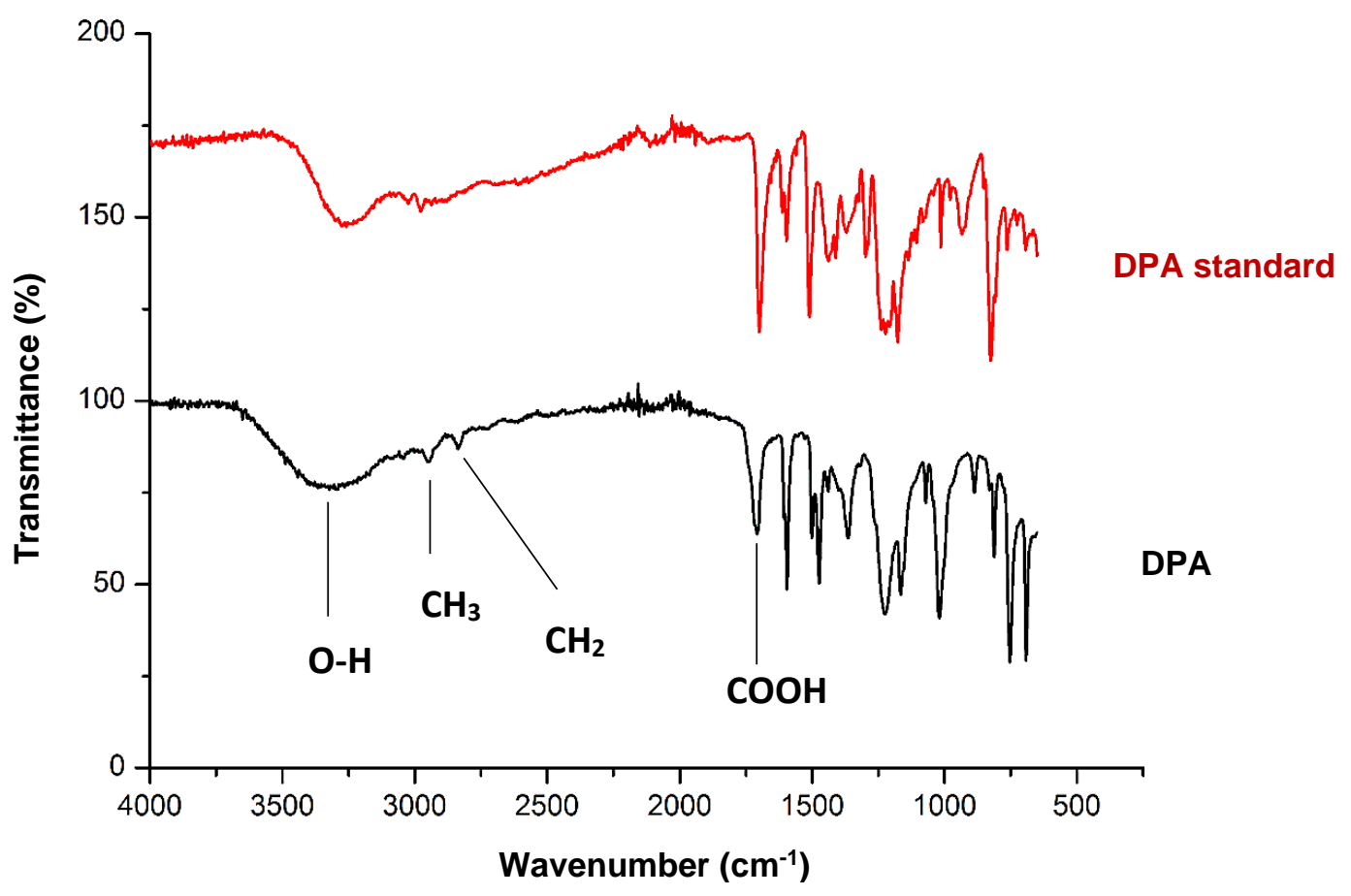

Fig. 5. FTIR scan of DPA standard vs DPA produced from commercial LA (this study) 
The absorbance bands associated with the functional groups of DPA are observed in Fig. 5 by wavenumbers: carboxylic acid, $\mathrm{COOH}\left(1741 \mathrm{~cm}^{-1}\right)$, alkane, $\mathrm{CH}_{3}$ (2862 to 2882 $\left.\mathrm{cm}^{-1}\right), \mathrm{CH}_{2}$ (2843 to $2863 \mathrm{~cm}^{-1}$ ), and hydroxyphenyl, $\mathrm{OH}$ (3650 to $3590 \mathrm{~cm}^{-1}$ ). The above functional groups indicate the presence of DPA in the analysed reaction product. The FTIR scans of both DPA and DPA standard include same functional groups; however, the shape of the peaks are not similar. This may be caused by the different production process of DPA or that the DPA produced in this study was analysed in a reaction product therefore it was not purified.

\section{Effect of the Catalysts on the Production of DPA}

The evaluation of the effect of catalysts in the condensation reaction of DPA was carried out using tosylic acid [TsOH], 1-butyl-3-methylimidazolium hydrogen sulphate [BMim] $\left[\mathrm{HSO}_{4}\right]$, 1-ethyl-3-methylimida-zolium tosylate [EMim][OTs], sulfuric acid $\left[\mathrm{H}_{2} \mathrm{SO}_{4}\right]$, and methanesulfonic acid $[\mathrm{MsOH}]$. Sulfuric acid yielded the maximum DPA yield of $74.0 \%$. ILs also showed high catalytic activity especially [BMim] $\left[\mathrm{HSO}_{4}\right]$ with a DPA yield of $68.2 \%$ followed by [EMim][OTs] with a DPA yield of 59.3\%, which is an advantage because ILs are environmentally friendly compared with sulfuric acid.

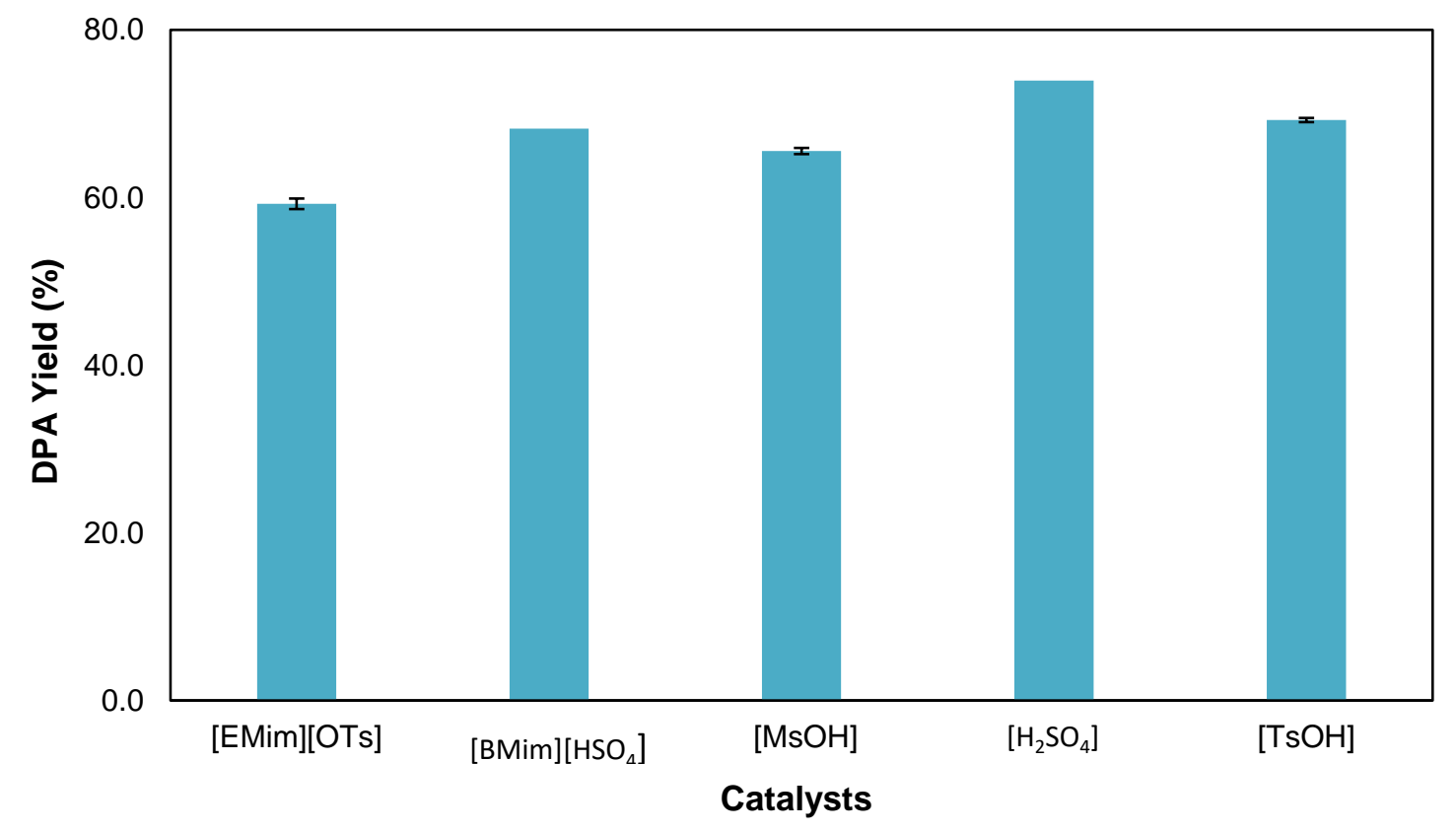

Fig. 6. Effect of catalysts on the condensation reaction of DPA

\section{Effect of the Ratio of LA to Phenol on the Production of DPA}

The effect of commercial LA to phenol ratio was studied by using the optimum values and only varying the commercial LA to phenol ratio. The following ratios (LA: phenol) were used: 1:4, 2:3, 2:4, 1:5, and 2:5. The results in Fig. 7 illustrate that increasing both LA and phenol increased the DPA yield. The 2:5 ratio yielded the highest DPA of $86.35 \%$, which is higher compared with the DPA yield obtained when using the control ratio (1:3). Utilizing higher ratio means more reactants are needed for the maximum DPA production, which will result in higher production cost. 


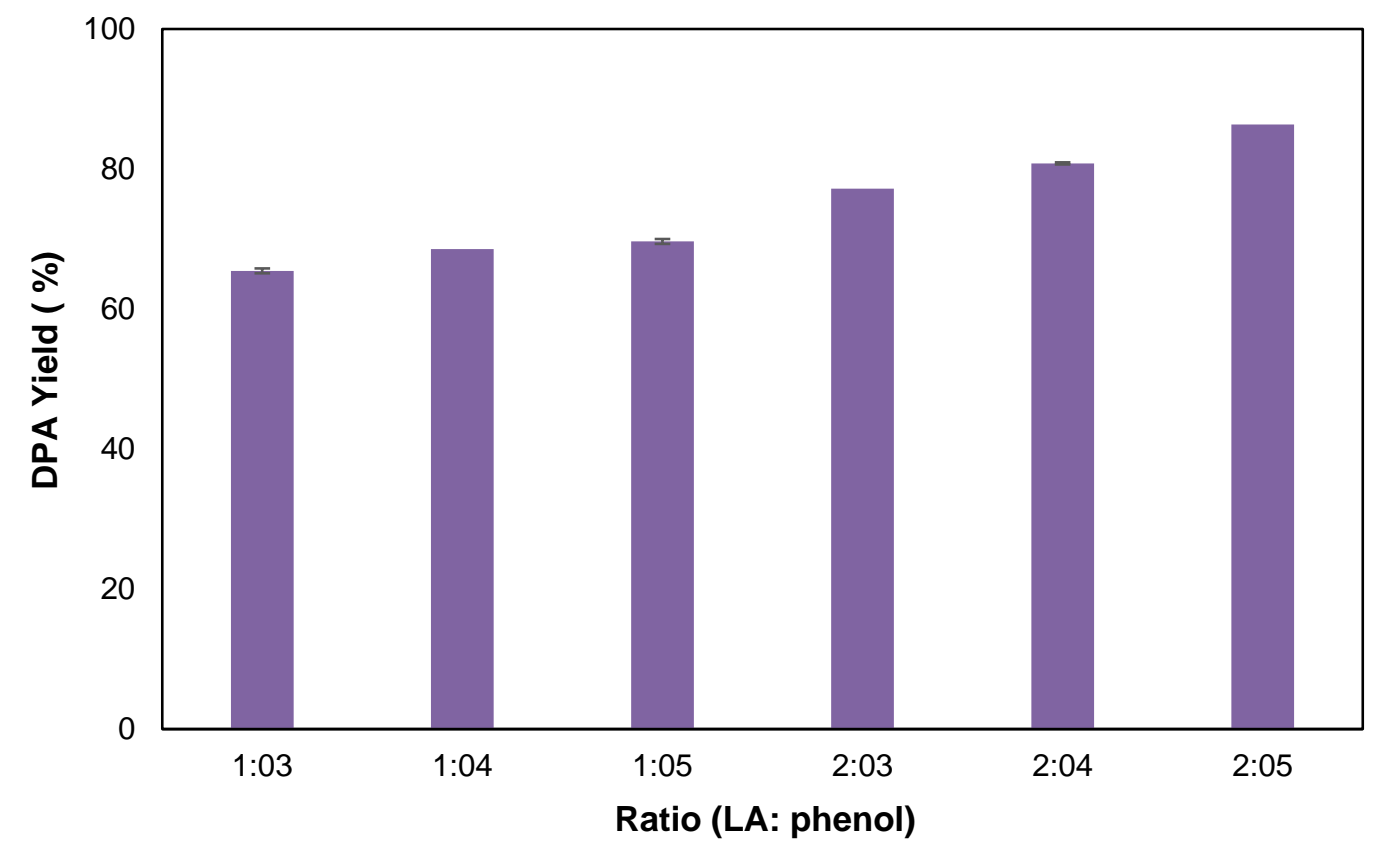

Fig. 7. Effect of LA: phenol ratio on DPA production

\section{DSB Derived LA Conversion to DPA}

\section{LA production from $D S B$}

The LA yield obtained in this work was $55 \%$, which is $0.4 \%$ higher than the smaller scale production of LA from DSB (Mthembu et al. 2020). This shows that there is no significant difference in LA yield when the reaction was upscaled.

\section{Condensation reaction of $L A$ derived from DSB into DPA}

The use of LA derived from DSB with the optimized conditions of $6 \mathrm{~h}, 75^{\circ} \mathrm{C}$, and $5.5 \mathrm{~g}$ of $\mathrm{MsOH}$ yielded a DPA of $64.5 \%$. This is comparable to that obtained from commercial LA. Thus, LA derived from DSB is a promising reactant for DPA production.

\section{CONCLUSIONS}

1. The production of diphenolic acid (DPA) from levulinic acid (LA) was optimized using methanesulfonic acid as a catalyst and commercial LA as the feedstock. The investigated factors were temperature, time, and catalyst loading. The optimum conditions were $75^{\circ} \mathrm{C}$, a reaction time of $6 \mathrm{~h}$, and $5.5 \mathrm{~g}$ of MSA, which yielded a maximum DPA yield of $65.8 \%$.

2. The response surface methodology and Box-Behnken design were used to optimize the DPA production from LA, where the ANOVA and parity plot indicated that the resultant quadratic response model was significant and that it can predict the DPA yield. The Pareto chart also revealed that temperature was the most influential factor towards DPA yield. 
3. The catalysts imparted different activities to the reaction system; different DPA yields were obtained. In general, acids yield high DPA compared with ionic liquids. However, 1-butyl-3-methylimidazolium hydrogen sulphate [BMim] $\left[\mathrm{HSO}_{4}\right]$ yielded higher DPA than the control catalyst MsOH. The advantage of ILs is that they can be re-used.

4. The effect of ratio of LA to phenol also showed that adding more phenol increased the DPA yield. This can be regarded as a disadvantage because a high volume of phenol will contribute to higher cost for the production of DPA. LA derived in this work from DSB produced $64.5 \%$ of DPA.

\section{ACKNOWLEDGMENTS}

The authors are grateful to L'Oréal-UNESCO for Women in Science Sub-Saharan Africa Regional fellowships, Durban University of Technology (DUT) for financial support and CSIR's Forestry and and Forest Products Research Centre in Durban.

\section{REFERENCES CITED}

Blegen, J. R. (1982). "Coating compositions based on polyester resins hardenable by vapor permeation for flexible supports," Belgian Patent No. 891465.

Bozell, J. J., Moens, L., Elliott, D. C., Wang, Y., Neuenscwander, G. G., Fitzpatrick, S. W., Bilski, R. J., and Jarnefeld, J. L. (2000). "Production of levulinic acid and use as a platform chemical for derived products," Resources, Conservation and Recycling 28, 227-239. DOI: 10.1016/S0921-3449(99)00047-6

Bozell, J. J., and Petersen, G. R. (2010). "Technology development forthe production of biobased products from biorefinery carbohydrates - the US Department of Energy's "Top 10" revisited," Green Chemistry 12, 539-554. DOI: 10.1039/B922014C

Cha, J. Y., and Hanna, M. A. (2002). "Levulinic acid production based on extrusion and pressurized batch reaction," Industrial Crops and Products 16, 109-118. DOI: 10.1016/S0926-6690(02)00033-X

Chafetz, H., Liu, C. S., Papke, B. L., and Kennedy, T. A. (1995). "Lubricating oil composition containing the reaction product of an alkenylsuccinimide with a bis(hydroxyaromatic) substituted carboxylic acid," U.S. Patent 5445750.

Chambon, C. L., Mkhize, T. Y., Reddy, P., Brandt-Talbot, A., Deenadayalu, N., Fennell, P. S., and Hallett, J. P. (2018). "Pretreatment of South African sugarcane bagasse using a low-cost protic ionic liquid: A comparison of whole, depithed, fibrous and pith bagasse fractions," Biotechnology for Biofuels 11, 247. DOI: 10.1186/s13068018-1247-0

Chandel, A. K., Antunes, F. A., Anjos, V., Bell, M. J. V., Rodrigues, L. N., Polikarpov, I., de Azevedo, E. R., Bernardinelli, O. D., Rosa, C. A., Pagnocca, F. C., and da Silva, S. S. (2014). "Multi-scale structural and chemical analysis of sugarcane bagasse in the process of sequential acid-base pretreatment and ethanol production by Scheffersomyces shehatae and Saccharomyces cerevisiae," Biotechnology for Biofuels 7, 63. DOI: 10.1186/1754-6834-7-63

Chen, H., Yu, B., and Jin, S. (2011). "Production of levulinic acid from steam exploded rice straw via solid superacid, $\mathrm{S}_{2} \mathrm{O}_{8}{ }^{2-} / \mathrm{ZrO}_{2}-\mathrm{SiO}_{2}-\mathrm{Sm}_{2} \mathrm{O}_{3}$," Bioresource Technology 
102, 3568-3570. DOI: 10.1016/j.biortech.2010.10.018

Ertl, J., Cerri, E., Rizzuto, M., and Caretti, D. (2014). "Natural derivatives of diphenolic acid as substitutes for bisphenol-A," AIP Conference Proceedings 1599, 326-329. DOI: $10.1063 / 1.4876844$

Guo, Y., Li, K., and Clark, J. C. (2007). "The synthesis of diphenolic acid using the periodic mesoporous $\mathrm{H}_{3} \mathrm{PW}_{12} \mathrm{O}_{40}$-silica composite catalysed reaction of levulinic acid," Green Chemistry 9, 839-841. DOI: 10.1039/B702739G

Hayes, D. J., Ross, J., Hayes, M. H. B., and Fitzpatrick, S. W. (2006). "The biofine process: Production of levulinic acid, furfural and formic acid from lignocellulosic feedstocks," in: Biorefineries-Industrial Processes and Product, B. Kamm, P. R. Gruber, and M. Kamm (eds.). Wiley-VCH, Weinheim, Germany, pp.139-164.

Holmen, R. E., and Olander, S. J. (1977). "Paint composition for making paved surfaces," U.S. Patent No. 4031048.

Kitano, M., Tanimoto, F., and Okabayashi, M. (1976). "Levulinic acid, a new chemical raw material. Its chemistry and use," Chemischer Informationsdienst 7, 25-29. DOI: 10.1002/chin.197603129

Li, K. X., Hu, J. L., Li, W., Ma, F. Y., Xu, L. L., and Guo, Y. H. (2009). “Design of mesostructured $\mathrm{H}_{3} \mathrm{PW}_{12} \mathrm{O}_{40}$-silica materials with controllable ordered and disordered pore geometries and their application for the synthesis of diphenolic acid," Journal of Materials Chemistry 19, 8628-8638. DOI: 10.1039/B910416J

Liu, H., Zeng, F., Deng, L., Liao, B., Pang, H., and Guo, Q. (2013). “Bronsted acidic ionic liquids catalyse the high yield production of diphenolic acid/esters from renewable levulinic acid," Green Chemistry 14, 81. DOI: 10.1039/C2GC36630D

Liu, Y., Zhang, Y., and Fang, Z. P. (2012). "Design synthesis, and application of novel flame retardants derived from biomass," BioResources 7(4), 4914-4925. DOI: $10.15376 /$ biores.7.4.4914-4925

Mkhize, T., Mthembu, L.D., Gupta, R., Kaur, A., Kuhad, R.C., Reddy, P., and Deenadayalu, N. (2016). "Enzymatic saccharification of acid/alkali pre-treated, millrun, and depithed sugarcane bagasse," BioResources 11(3), 6267-6285. DOI: 10.15376/biores.11.3.6267-6285

Mthembu, L. D. (2016). Production of Levulinic Acid from Sugarcane Bagasse, Master's Thesis, Durban University of Technology, Durban, South Africa.

Mthembu, L. D., Lokhat, D., Gupta, R., and Deenadayalu, N. (2020). “Optimization of levulinic acid production from depithed sugarcane bagasse in 1-ethyl-3methylimidazolium hydrogen sulfate [EMim][HSO 4$]$," Waste and Biomass Valorization 1-13. DOI: 10.1007/s12649-020-01221-z

Shen, Y., Sun, J., Wang, B., Xu, F., and Sun, R. (2014). "Catalytic synthesis of diphenolic acid from LA over Bronsted acidic ionic liquids," BioResources 9(2), 3264-3275. DOI: 10.15376/biores.9.2.3264-3275

Yan, K., and Chen, A. (2013). "Efficient hydrogenation of biomass-derived furfural and levulinic acid on the facilely synthesized noble-metal-free $\mathrm{Cu}-\mathrm{Cr}$ catalyst," Energy 58, 357-363. DOI: 10.1016/j.energy.2013.05.035

Yan, K., Lafleur, T., Wu, G., Liao, J., Ceng, C., and Xie, X. (2013). "Highly selective production of value-added $\gamma$-valerolactone from biomass-derived levulinic acid using the robust Pd nanoparticles," Applied Catalysis A: General 468, 52-58. DOI: 10.1016/j.apcata.2013.08.037

Yu, X., Guo, Y., Li, K., Yang, X., Xu, L., Guo, Y., and Hu, J. (2008). “Catalytic synthesis of diphenolic acid from levulinic acid over cesium partly substituted Wells- 
Dawson type heteropolyacid," Journal of Molecular Catalysis A: Chemical 290, $44-$ 53. DOI: 10.1016/j.molcata.2008.04.023

Zhang, J., Wu, S., Li, B., and Zhang, H. (2012). "Advances in the catalytic production of valuable levulinic acid derivatives," ChemCatChem 4, 1230-1237.

DOI: $10.1002 /$ cctc. 201200113

Zhang, Z., Jia, Q., and Liao, W. (2015). "Chapter 277 - Progress in the separation processes for rare earth resources," in: Handbook on the Physics and Chemistry of Rare Earths, J.-C. Bünzli and V. K. Pecharsky (eds.), Elsevier, Amsterdam, 48, pp. 287-376. DOI: 10.1016/B978-0-444-63483-2.00004-1

Zhao, D., Wu, M., Kou, Y., Min, E. (2002). "Ionic liquids: Applications in catalysis," Catalysis Today 74, 157-189. DOI: 10.1016/S0920-5861(01)00541-7

Zuñiga, C., Lligadas, G., Ronda, J.C., Galià, M., and Cádiz, V. (2017). "Polybenzoxazine materials from renewable diphenolic acid," in: Advanced and Emerging Polybenzoxazine Science and Technology, Elsevier, Amsterdam, pp. 427-449.

Article submitted: November 30, 2020; Peer review completed: January 2, 2021; Revised version received: January 27, 2021; Accepted: January 28, 2021; Published: February 1, 2021.

DOI: $10.15376 /$ biores.16.2.2235-2248 